\title{
Ciências, intercâmbios e circulação: as conexões entre Brasil e EUA
}

\section{Science, exchanges, and circulation: connections between Brazil and the United States}

\author{
Ana Cristina Santos Matos Rocha ${ }^{i}$ \\ i Pesquisadora de pós-doutorado, Escola de Filosofia, Letras e Ciências Humanas/ \\ Universidade Federal de São Paulo - campus Guarulhos. \\ Guarulhos - SP - Brasil \\ orcid.org/0000-0001-5718-1293 \\ anasmrocha@yahoo.com.br
}

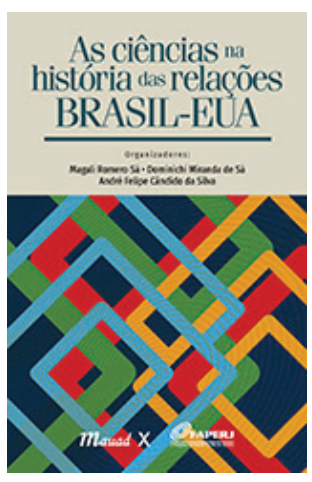

SÁ, Magali Romero; SÁ, Dominichi Miranda de; SILVA, André Felipe Cândido da (org.). As ciências na história das relações Brasil-EUA. Rio de Janeiro: Mauad-X; Faperj, 2020. 436p.
Organizado pelos pesquisadores da Casa de Oswaldo Cruz Magali Sá, Domichi Sá e André Silva, As ciências na história das relações Brasil-EUA reúne textos que analisam as conexões estabelecidas entre esses dois países tendo como ponto de partida projetos e redes de pesquisa que sinalizam como a diplomacia cultural foi, muitas vezes, também científica. Interesses econômicos e políticos não estão apartados nessas narrativas, sinalizadoras das múltiplas convergências que marcaram essas relações ao longo do século XX. Os 17 capítulos que integram o livro compõem esse recorte temporal amplo, assim como os campos de investigação que são eleitos para análise: agronomia, medicina, física, genética, antropologia, ciências sociais, biologia, entre outros.

Desse modo, o primeiro capítulo trabalha com uma perspectiva de aproximação dos EUA a partir da retórica do pan-americanismo, tomando como objeto as narrativas do Boletim da União Panamericana do começo do século XX, enquanto o segundo analisa a expedição Roosevelt-Rondon (1913-1914). Já o último capítulo examina a constituição e a institucionalização do campo da biologia da conservação e os projetos a ele relacionados durante a segunda metade do século XX. As diferenças temporal e disciplinar se refletem no modo como os vocabulários pelos quais essas relações se estabeleceram também foram mudando de significado. Assim a "natureza" dos boletins da União Pan-Americana ou da viagem de um Roosevelt "aventureiro" e "caçador" (Sá, Sá, Silva, 2020, p.59) não é a mesma dos projetos de conservação desenvolvidos em parceria pelos ambientalistas, brasileiros e estrangeiros. Entre uma natureza e outra, cabe ao leitor estabelecer uma linha por vezes impossível de ser definida, porque heterogênea em suas associações. O mesmo pode ser dito se tomarmos a Amazônia como elemento aglutinador de alguns dos capítulos. 
É justamente nessa heterogeneidade que se encontra a força do livro. Situado em uma perspectiva que procura complexificar o discurso do imperialismo e as assimetrias que são a marca das relações entre os dois países, as análises nele desenvolvidas expressam variáveis fundamentais para entender essas relações. Aqui estão os espaços de negociação e multivocalidade apontados por Gilbert Joseph e materializados nos "encontros" entre EUA e Brasil, em um contexto em que "estrangeiros, ideias, commodities e instituições foram recebidos, contestados e apropriados pela América Latina dos séculos XIX e XX" (Joseph, LeGrand, Salvatore, 2006, p.5). Seguindo os pressupostos de Kapil Raj (2007), também aqui a circulação de atores e ideias é pensada a partir de uma variedade de escalas que são encaradas como "parte estruturante da própria produção do conhecimento científico" (Sá, Sá, Silva, 2020, p.16).

Em contrapartida, a leitura nos oferece a oportunidade de identificar padrões institucionais que perpassam os temas ali explorados, ao mesmo tempo que materializam as especificidades de cada caso. Assim, embora tenha como premissa a análise de dinâmicas de pesquisa desenvolvidas no Brasil, o livro aborda questões relacionadas às políticas adotadas por instituições norte-americanas, como o caso da Fundação Rockefeller e do Office of the Coordinator of Inter-American Affairs (Ociaa), em interação com o repertório nacional. Aqui entram as conexões que se beneficiaram do contexto do "esforço de guerra", como o campo da cardiologia, com a visita de Frank Wilson ao Brasil, ou o da física, com a visita de Arthur Compton.

Esses e outros capítulos sinalizam como as dinâmicas de circulação de pessoas, artefatos e ideias, a partir da dupla treinamento de pesquisadores brasileiros no exterior e visita de pesquisadores estrangeiros aos espaços de pesquisa nacionais, tiveram como resultado a construção de redes de investigação que muitas vezes transcenderam os propósitos iniciais que motivaram seus financiamentos. Embora os cientistas norte-americanos que desenvolviam pesquisas no Brasil tenham frequentemente se tornado mediadores nessas negociações, a conexão deles com as políticas de aproximação de seu país não é o único fator em jogo. Exemplo eloquente é o do posicionamento de George Meyers diante do projeto da Divisão de Recursos Alimentares da Ociaa voltado para a pesca na Amazônia (Sá, Sá, Silva, 2020, p.131).

Além do campo da medicina e da saúde, as políticas de financiamento da Fundação Rockefeller estão presentes nos projetos desenvolvidos nas áreas de agricultura, pecuária, física, genética. Um capítulo do livro destaca a atuação de Harry Miller, que foi analisada a partir dos projetos de pesquisa desenvolvidos em São Paulo. Como diretor assistente da Divisão de Ciências Naturais da mencionada fundação, Miller também é um dos interlocutores de Dobzhansky, que relata a ele os avanços da pesquisa em genética desenvolvida no Brasil, e de Felisberto Camargo, do Instituto Agronômico do Norte (IAN), além de mediador no financiamento das pesquisas desenvolvidas no Departamento de Física da Universidade de São Paulo.

No contexto da discussão das relações de poder, análises mais circunscritas do trabalho desenvolvido pelos cientistas também sinalizam as possibilidades de cooperação que, embora inseridas no campo das "assimetrias em termos de disponibilidade de recursos para a pesquisa, capital simbólico e de acesso aos fóruns de validação científica, combinaram-se com um diálogo simétrico no tocante à capacidade intelectual e habilidade de investigação" 
(Sá, Sá, Silva, 2020, p.353). Esse é o caso do agrônomo brasileiro Agesilau Bitancourt e da micologista norte-americana Eliza Jenkins, como afirma André Silva. De forma geral, os capítulos sinalizam como os brasileiros negociaram com os norte-americanos a partir de seus interesses, ao mesmo tempo que cientistas norte-americanos se beneficiaram dos projetos que desenvolveram no Brasil.

Assim, longe de estabelecer um modelo das "relações científicas" que se desenvolveram entre Brasil e EUA, o que esse livro nos mostra é a amplitude de seus significados. Contribui, portanto, para uma história que se propõe a investigar as dimensões institucionais, disciplinares, nacionais e transnacionais do conhecimento científico, sem no entanto perder de vista a interação dessas dimensões dentro de seus contextos políticos particulares. Nesse sentido, sinaliza como o campo da história da ciência contribui para esse debate, já tradicional no campo das relações internacionais.

\section{AGRADECIMENTOS}

Fundação de Amparo à Pesquisa do Estado de São Paulo, processo n.2019/04525-7.

\section{REFERÊNCIAS}

JOSEPH, Gilbert; LEGRAND, Catherine; SALVATORE, Ricardo (ed.). Close encounters of empire: writing the cultural history of US-Latin American relations. Durham: Duke University Press, 2006.

RAJ, Kapil. Relocating modern science: circulation and the construction of knowledge in South Asia and Europe, 1650-1900. New York: Palgrave Macmillan, 2007.

SÁ, Magali Romero; SÁ, Dominichi Miranda de; SILVA, André Felipe Cândido da (org.). As ciências na história das relações Brasil-EUA. Rio de Janeiro: Mauad-X; Faperj, 2020. 